\title{
Influencing Practice through the Development of Clear and Transparent Guidelines for the Recognition of Prior Learning (RPL)
}

\author{
By Malcolm Day*
}

\begin{abstract}
This study has used quality assurance processes from business and industry to benchmark the role of the RPL practitioner so that the process of assessment could be made explicit to all involved in the RPL process. An action research approach has been taken using mixed methodology. The following research questions were asked: what principles are common to RPL practice; can these principles be developed as benchmarks to make RPL practice more explicit; how might emergent benchmarks inform the career of the RPL practitioner? Three cycles of research were undertaken over a 15-year period. The first cycle was conducted within the tertiary sector in Canada. The second cycle was undertaken in South Africa with a cohort of university academics and a cohort of nurse educators. A third cycle was undertaken with nurse educators in the UK, which is the focus of this report. It was found that when resources are optimal the practitioner uses assessment methods based on the individual needs of the learner. These methods are holistic and contrary to the literature are inclusive, rather than exclusive or specific to, a competency or developmental approach to RPL. A career pathway for the RPL practitioner has been identified. This demonstrates the characteristic way the practitioner engages with an organisation to bring about changes in assessment practice. The functional role of the RPL practitioner has also been identified. This provides an explicit framework for practice that may be used to complement and support the career of the RPL practitioner and to construct a model for RPL practice.
\end{abstract}

Keywords: Assessment, Benchmarking, Higher Education, Nursing , Recognition of Prior Learning

\section{Introduction}

\section{What is Recognition of Prior Learning?}

The process used to gauge learning that has occurred at some time in the past is known as Recognition of Prior Learning or RPL (QAA 2013). The Canadian Association for Prior Learning (2000) states that RPL is a systematic process that involves the identification, documentation, assessment and recognition of learning. This learning may have occurred as a result of a programme of study, experience gained at work, during voluntary activities in the home or during leisure pursuit. The credit that may be awarded as a consequence of RPL can be used to gain entry into a programme of study, or it can take the form of exemption within a course of study. Partial credit towards an academic award can also be awarded (QAA 2004). The type and amount of credit that is awarded may be based on certificates the learner has gained which demonstrate that learning has already been assessed. Alternatively, the credit awarded may take into account learning from experience. In the latter case,

\footnotetext{
* Assistant Professor, School of Health Sciences, University Nottingham, England, UK.
} 
credit is awarded for learning that can be demonstrated, not for the experience itself. This credit is considered to be of equal standing to that awarded to others who have followed a traditional programme of study (QAA 2004). Although RPL has been in use in UK nurse education for some time (Scott 2010) it has assumed a new importance as the Nursing and Midwifery Council have indicated that up to $50 \%$ of a pre registration nursing programme (both theory and practice) can now be achieved by RPL (Long 2010).

Two contrasting models for RPL have emerged since the 1970s (Butterworth 1992). First, the credit exchange or product approach. This has been used, for example, within competency-based vocational education. Here, the learner identifies areas of a programme that s/he has achieved, and then offers evidence of these past achievements contained within a portfolio. Credit is awarded if the assessor and verifier agree that evidence contained within the portfolio proves possession of competence. Breier (2011) refers to this as the procrustean approach, where only those aspects of prior learning that match the prescribed outcomes are recognised (Harris 1999). Second, the developmental or process-based approach, which emphasises the use of documentary evidence supported by reflective commentary. The learner's reflection is supported by discussions with a tutor. The purpose of these discussions is to support the learner's personal and professional development. The assessor judges both the evidence and the reflective commentary before making a recommendation for academic credit. Breier (2011) refers to this as learning and development RP. Here the candidate's prior learning is manipulated to conform to "canonical bodies of knowledge" (Harris 1999: 131).

Several academics have argued that the credit exchange model is limiting, for example, Trowler (1996) has stated it is derived from a behavioural model of learning and has no place in higher-level learning. Butterworth (1992) explains that the developmental model provides a more legitimate pedagogy for higher education as it assists the learner to undertake an analysis of their own practice and to increase their professional expertise. This view is supported by Andersson (2006) who states the purpose of the developmental approach is to inform and change the continuing learning process. It is also supported by Popova-Gonci (2009) who states that institutions should celebrate RPL as a learning process. This idea is explored further by Harris (1999, 2000, 2013) when describing the Trojan horse model of RPL, where attempts are made to value prior learning in and of itself rather than its degree of fit to learning outcomes. Osman (2004) refers to this as transformational RPL.

More recently, a study by Flemish researchers (Swegers et al. 2009) has identified two types of RPL portfolio: the recognition portfolio, and the acknowledgement portfolio. The recognition portfolio mainly fulfils a formative function, whilst the function of the acknowledgement portfolio is primarily summative. Swegers et al. (2009) indicate that the processes involved in developing either are not mutually exclusive. This is interesting as it suggests that a more integrated approach to RPL is now be emerging. 


\section{What Counts as an Evidence Base for RPL?}

Evans (2000: 49) states that the evolution of RPL has largely been based on "happenstance, coincidences and flukes of timing". Konrad (2010) indicates there is little scientific evidence to support the practice of RPL in Europe. For example, in 2007, Manoudi reported that a national certification system for the validation of informal and non formal learning had yet to be developed in Greece. Five years later Lafont and Pariat (2012) reported that a system for the validation of experiential learning had been developed. However, a recent trawl of seven "top ranked" universities in Greece (Short courses portal 2016) has failed to identify any RPL programmes on their websites. Lafont and Pariat (2012) indicate that this finding is fairly typical of many European member states with the exception of Finland, France, Norway and the UK. Further, Harris and Wihak (2011) indicate that international RPL scholars remain few and far between and that much RPL research is atheoretical and uncritical. In addition, RPL research tends to be fragmented as it is does not build on what has come before (Harris and Wihak 2011). In order to determine what counts as an appropriate evidence base for the practice of RPL the following have been considered the: current state of the RPL literature; methodology used in RPL research; scope of RPL research; and future directions for RPL research. Each of these issues will now be discussed.

First, with respect to the current state of RPL literature, Joosten-ten Brinke et al. (2008) argue that RPL literature is largely descriptive. Porkony (2011) states the literature tends to be promotional. Wihak (2012) argues that most academic publications treat RPL research very generally. This creates difficulties for those involved in RPL research. First, because the key words, phrases and acronyms used to describe the field may vary, making the use of standard research databases a challenge. Second, much of the research into RPL is policy focussed and sponsored by government departments. Wihak (2012) refers to this as "grey literature" and points out that this is not indexed in standard academic databases. Third, Wihak (2012) indicates that RPL research tends to be multidisciplinary. Therefore, any new ideas tend to be dispersed across the many and diverse publications that represent the higher education disciplines.

Second, in reference to the methodology of RPL research, Andersson and Fejes (2011) and Harris and Wihak (2011) indicate that the dominant methodology is qualitative. The lack of quantitative research could be explained by a dearth of official statistics and data on RPL making it difficult to follow-up and analyse long-term trends and effects (Andersson \& Fejes 2011). Further, Harris and Wihak (2012) indicate that RPL research consists predominantly of small-scale retrospective studies, consisting of action research, case studies and evaluations of pilot projects. Friesen (2011) argues for a multifocal approach to RPL research including the application of multiple theories and methodologies to what he believes is an emerging field of practice. Van Cleef (2011) has identified a typology for Canadian RPL research, including experimental quantitative research, non-experimental 
quantitative research, qualitative research and mixed methods research. These are presented sequentially and are cross-referenced chronologically, either as retrospective, cross-sectional or prospective studies. In addition, experimental research and non-experimental research each have three possible sub-types: descriptive, explanatory and predictive. For example, the Canadian RPL Benchmarking Study (Day 2001a and 2001b) has been categorised as a community-based study undertaken with RPL practitioners that is qualitative, descriptive, non-experimental and cross-sectional (Van Cleef 2011: 75).

Third, concerning the scope of RPL research, Andersson and Fejes (2011: 228) identify six emerging RPL research themes for Sweden since the year 2000. These themes include historical studies, research on the recognition of vocational competence, immigration and gender, theories of assessment, RPL governance and comparative studies of RPL. Cameron (2011) outlines the research themes that have emerged in Australia from 1990-2010. These themes include the benefits and drivers for RPL, barriers to RPL, access and social inclusion, recognition of workplace learning, use of web-based technologies, and researching and building practitioner capability. Travers (2011) indicates that research in the US has primarily been concerned with barriers and enablers of practice, the impact of RPL on student success rates, and the transformational effects of RPL on individuals and their learning. Whilst, Porkony (2011) indicates that much of the research undertaken in the UK since 2007 relates to the use of RPL in work-based learning.

Fourth, the future direction for RPL research, much of the research literature is concerned with implementation rather than the concept of RPL itself. Moreover, there is a paucity of research and critical analysis of macro influences on RPL, and a lack of statistical data on the uptake of RPL (Cameron 2011). Van Cleef (2011) argues that there are under utilised types of research that could move RPL research forward, from small-scale, descriptive and exploratory qualitative studies to quantitative experimental studies. Whittaker (2011) identifies possibilities for future research in Scotland, which includes the development of RPL toolkits based on models of good practice, awareness raising and marketing strategies to highlight the benefits of RPL to learners, exploration of ways to secure and deploy RPL resources effectively and the capacity-building measures required to support the development of RPL. This study makes a small contribution to Whittaker's agenda through its work in Canada, South Africa and the UK. For example, the Canadian Benchmarking has produced a self-assessment tool for RPL practitioners (Day 2013). Also, in South Africa a series of RPL capacity-building workshops have been developed (Day and Gawe 2003, Day 2015b).

What is Benchmarking?

Benchmarking is a practice that allows a service to determine its standing within its field. Organizations use benchmarking to solve problems, plan and set goals, and improve processes. The Higher Education Funding Council for England (HEFCE 2010) defines benchmarking as: 
A process through which practices are analysed to provide a standard measurement ("benchmark") of effective performance within an organisation (such as a university). Benchmarks are also used to compare performance with other organisations and other sectors.

Benchmarking in health care has been in place for over a decade through the: "Essence of Care Project" which has now identified over a dozen benchmarks for care delivery including: privacy and dignity; food and nutrition; personal and oral hygiene (Department of Health 2010). In this study, the practice of RPL in UK Schools of Nursing is compared with benchmarks for RPL developed by the Canadian Association for Prior Learning Assessment or CAPLA (2000).

\section{Methodology}

\section{The Research Problem}

Successive Government strategies for higher education have indicated a clear intention to expand student numbers and increase participation rates by developing the credit based systems already operating within English Universities (Department for Education and Skills 2003). In 2004, the Quality Assurance Agency for Higher education (the QAA) developed RPL guidelines for faculties of higher education (QAA 2004). These guidelines offered principles and prompts for universities undertaking RPL and complemented the higher education qualifications framework published by QAA (2001). However, a study by the National Institute for Adult Continuing Education (NIACE) in 2008 reported that RPL in Higher Education was still characterized by inconsistency and lack of coherence (NIACE 2008).

Although there is an apparent dearth of research based literature relating to the field of RPL a brief literature review was undertaken to gain an overall impression of issues relating to RPL practice, and (perhaps) to explain some of the findings of NIACE (2008). This review identified what appeared to be significant tensions underpinning RPL work. These are categorised in Table 1 and have been used to develop an investigative framework for this study. The tensions appear to focus on the relative merits of either a credit exchange (Product) or a developmental model of RPL (Process). However, in the UK the role and responsibilities of the RPL Practitioner have developed in a rather uncertain and haphazard way and it appears that this uncertainty has added to the confusion and role strain experienced by university staff, who are undertaking RPL activities in addition to their other duties. Further, it seems that RPL is now being practiced in a less divergent way than the previous literature suggested. As a consequence practitioners appear to be taking a more pragmatic approach towards assessment, in order to resolve the tension and discord that is underpinning their practice. This study aimed to challenge these assumptions. It did this by drawing on the work previously undertaken in 
Canada (Day 2001a and 2001b) and South Africa (Day and Gawe 2003, Day 2015b) to systematically codify RPL practice so that processes and procedures might become more transparent, clear and explicit. Thus, the main thesis of this study was that guidelines or benchmarks for RPL practice were best developed by practitioners (not HE institutions or regulatory agencies) and then adapted through practice in order to minimise discord and achieve resolution or congruence.

Table 1. The Tensions Underlying RPL Practice

\section{Objectivity versus Bias}

Academics have higher expectations of RPL students than those who are attending taught courses, and are therefore biased in the way they assess non-institutional learning. For example, see Merrifield et al. (2000).

\section{Equality versus Elitism}

Professions are now considering alternative forms of entry for individuals with vocational qualifications. There is a concern that this may lead to a drop in standards. For example, see Porkony (2011).

Internalisation versus Alienation of learning

There is a belief that RPL activity may become so focussed on meeting assessment outcomes that learners become alienated from the learning they have experienced. For example, see West and Fraser (1993), Trowler (1996), Peters (2006) and Porkony (2011).

\section{Quality versus Excessive Surveillance}

The need to quality assure assessment outcomes must be balanced against the purpose of the assessment, as well as the desire for utility For example, see Andersson (2006).

\section{Congruence versus Discord}

If academics cannot agree that RPL is a systematic and rigorous form of assessment (congruence) perhaps it is not surprising that students also have difficulty in understanding the process, and often have unrealistic expectations of RPL (discord). For example, see Merrifield et al. (2000).

The following research questions were posed: (1) what principles are common to RPL practice in UK Higher Education Institutions (HEIs)? (2) Can these principles be developed as a set of benchmarks to make the practice of APL more explicit? (3) How might emergent benchmarks inform the career of RPL practitioners? The outcomes of the first and second research question have already been reported (Day 2011a, 2011b). This article focuses on the outcomes of the third question. That is: How might agreed upon benchmarks inform the career of the RPL practitioner?"

\section{The Sample}

In order to gain a clear and accurate picture of RPL practice it was important to determine whether practitioners: were supported by regular and sustained funding; working within established policy and procedure for RPL; and processed significant numbers of RPL candidates. These essential requirements were adopted as inclusion criteria for the study and an initial 
screening survey was sent to Heads of Schools of Nursing in England, Northern Ireland, Scotland and Wales $(\mathrm{N}=66)$ in order to identify a sample that met these requirements. The returns from the screening survey identified a sample of 22 practitioners who met the inclusion criteria - these were included in the study as "Expert" practitioners. Those who did not meet the inclusion criteria were included as "Novices" $(\mathrm{N}=12)$. The total number of participants included in the study was 34 . There were no responses from Scotland.

\section{Ethical Issues}

Although research ethics committee approval was required before the study was undertaken in Canada, none of the institutions participating in the UK study required formal research ethics committee (REC) approval. This was in line with UK guidelines for research governance, which stated that research involving non NHS staff, or NHS staff who are recruited by virtue of their professional role (in this case teaching staff) does not require formal ethical approval (DH 2011). However, many writers including Harris (2013) stressed the importance of RPL as an agent for democracy and social change. Therefore, it was felt necessary to develop ethical guidelines that supported these key principles. In particular, attention was paid to: the informed consent of participants; the right of participants to "opt out" of the study; and nondisclosure of information to third parties. For example, some responses in this study are reported anonymously in order to maintain institutional confidentiality and protect the individual's identity.

\section{The Benchmarking Survey}

The benchmarking survey was based on the questionnaire developed for the Canadian RPL bench marking study (CAPLA 2000). The items were tested prior to their use with 17 practitioners who were a mix of experts and novices. Those who were consulted felt that the questionnaire items were representative of RPL functions in the UK. No difficulty was reported with language, and all questionnaires were completed within a reasonable period of time. Therefore, all of the original items were retained and included in the survey, which was administered to Experts $(\mathrm{N}=22)$ and Novices $(\mathrm{N}=12)$ from 34 Schools of Nursing. Each was asked to consider whether the benchmarks described their current practice. They were asked to indicate "Yes" (it did), "No", (it did not), or if they were "Not Sure". Respondents were asked to justify their response by adding comments and to make relevant changes to the language used in the benchmarks. Twenty-one questionnaires were returned (a response rate of $61 \%$ ). Thirteen were returned by Experts. Eight were returned by Novices. One novice indicated that he/she was not involved in nursing education - his/her response was discarded. Five experts (23\%) left the study before they completed the questionnaire. Three left because of pressure of work. Two left due to changes in role. 
A bivariate analysis of responses to the benchmarking survey showed that both Experts and Novices agreed that the functions and activities contained within the bench marked items were an accurate description of their role (Table 2). A qualitative analysis of the additional comments received during the survey also indicated that practitioners appeared to combine credit based (product) and developmental (process) approaches to meet the individual needs of the learner, as well as the demands of the workplace. For example one expert commented:

"The evidence required will depend on the size of the credit claimed, the level, the course against which the claim is made and the claim itselfwhether APCL or APEL or both combined. Thus each situation has to be prepared and evidence individually."

Table 2. Newly Emerging Benchmarks for RPL Practice

\section{Key Purpose}

The key purpose of the RPL Practitioner in UK Schools of Nursing and Midwifery is to: Review progress and/or assess achievements; so that individuals and organisations can achieve their personal development and/or education and training objectives. This includes assessment of individuals for academic credit and professional certification.

The main functions and activities of the RPL Practitioner's role are to:

\section{Function 1 - Prepare the Individual for Assessment. This includes the} following activities:

(a) Help the individual to identify relevant learning outcomes;

(b) Agree to and review an action plan for demonstration of prior learning. The action plan may be a verbal or written agreement between the RPL practitioner and the learner. It may also take the form of a learning contract;

(c) Help the individual to prepare and present evidence for assessment.

Function 2 -Assess the Individual. This includes the following activities:

(a) Progress formative assessment activities and judge evidence and provide feedback. Formative assessments are designed to provide learners with feedback on progress and inform development, but do not contribute towards the overall assessment (QAA 2000);

(b) Contribute to making a summative assessment decision using differing sources of evidence and provide appropriate feedback. Summative assessments provide a measure of achievement or failure made in respect of a learner's performance in relation to the intended learning outcomes of a programme of study (QAA 2000);

(c) Contribute to making a summative assessment decision using differing sources of evidence and provide appropriate feedback.

NB. RPL Practitioners may carry out both of the above functions.

Also, from the comments received, practice did not appear to be determined by any particular learning theory. Rather practice appeared to be context dependent and influenced by: time and resources and university regulations. For example, one expert commented: 
"In our circumstances with confederation contracts, candidates only find out a few weeks before the commencement of a course that they are attending, therefore our schema is often time limited."

Table 3 summarises the categories and themes emerging from the additional comments received from the benchmarking survey of practice. These were explored further using focus group work and depth interviews in order to verify or refute the comments emerging from the benchmarking survey.

Table 3. Factors Influencing RPL Practice: Results from the Benchmarking Survey

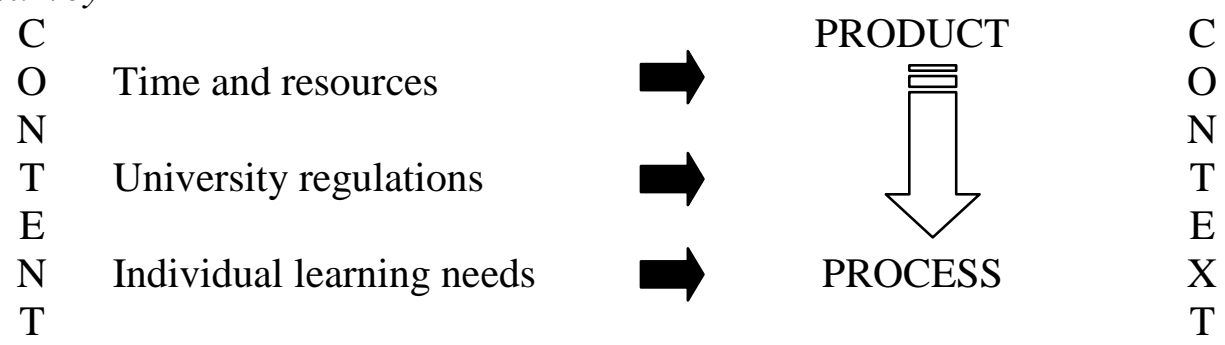

\section{The Focus Group}

A focus group was conducted with 10 informants. Each had completed the bench marking survey. Each was provided with an activity sheet to complete prior to the focus group meeting, which included the following questions: (1) what are the factors which might influence your approach towards RPL? (2) How might external factors influence your approach to RPL? (3) How might internal factors influence your choice of approach? Participants were asked to report back on their responses to the activity sheet. Their discussions were audio taped. The tapes were transcribed and fed back to participants for comment. The transcripts were then compared with the themes that had emerged from the survey of practice (Table 3). This enabled the researcher to corroborate and develop emergent themes, and to identify any gaps in data collection. For example, much of the group discussion focused on factors influencing practice with few specific examples given of how practice had changed. Therefore, it was necessary to draw out specific examples of any changes in practice during the depth interviews.

\section{Depth Interviews}

Interviews were conducted with 4 participants. Each was provided with a list of the following questions prior to interview: (1) how has the availability of time and resources impacted on your practice? (2) How have university regulations impacted on your practice? (3) Have your methods of assessing prior learning changed in any way. Please give one specific example? (4) Practitioners in this study have indicated that they utilise credit based and 
developmental approaches to RPL. Where would you place yourself on this continuum? Interviews were audio taped. The tapes were transcribed and fed back to participants for comment. No further responses were received.

\section{Data Analysis}

Comments emerging from the benchmarking survey were examined to explain individual differences in practice and the emergent themes were used to construct questions for focus group and depth interviews. Data emerging from focus group and depth interviews was then subjected to the analytical techniques described by Strauss and Corbin (1998). This involved the following activities: (1) the development of categories or codes based on the similarity or dissimilarity of content; (2) a comparison of each incident with the category to determine if each incident fitted; (3) an examination of categories for uniformity and any differences; (4) a review of the literature to see how well the findings fitted with existing research; and (5) identification of a conceptual schemata which accounted for most of the relationships or patterns that had been observed. The categories and themes that emerged from this analysis are reported in Table 4.

Table 4. Categories and Themes Emerging from Interviews and Focus Group Work

\begin{tabular}{|l|l|}
\hline Category One: Influencing Factors: & Category Two: Assessment Methods: \\
\hline Theme (a): University Regulations: & Theme $(\boldsymbol{a})$ : RPL as a Product: \\
\hline Empowerment & For specific credit \\
Initiation & Products from work \\
Adjustment & Transcripts \\
Adaptation & Certificates \\
Resolution & Assignments \\
Internalisation & \\
Liberation & Theme $(\boldsymbol{b})$ : PLA as a Process: \\
\hline Theme (b): Time and Resources: & For general credit \\
\hline Intensification & Reflective writing \\
Academic Gate keeping & Whole person \\
Academic Rigour & Self assessment \\
Role strain & Profiling \\
Role conflict & \\
Nailing Colours to the Mast & \\
Attrition & \\
Building Capacity & \\
Expert & \\
\hline & Theme $(\boldsymbol{c}):$ A continuum for PLA practice \\
\hline & Expert For specific and general credit \\
& Certificated and experiential learning \\
& RPL Workshops \\
& Individual Profiling \\
\hline
\end{tabular}




\section{Results}

The categories and themes outlined in Table 4 enabled the researcher to construct a schema that best describes the activities of the RPL practitioner in UK Schools of Nursing (Table 5) which is now discussed.

Table 5. The Career of the RPL Practitioner (Day 2012, 2013, 2015a, 2015b)

Influencing Factors (e.g. time, resources, university regulations, etc.)

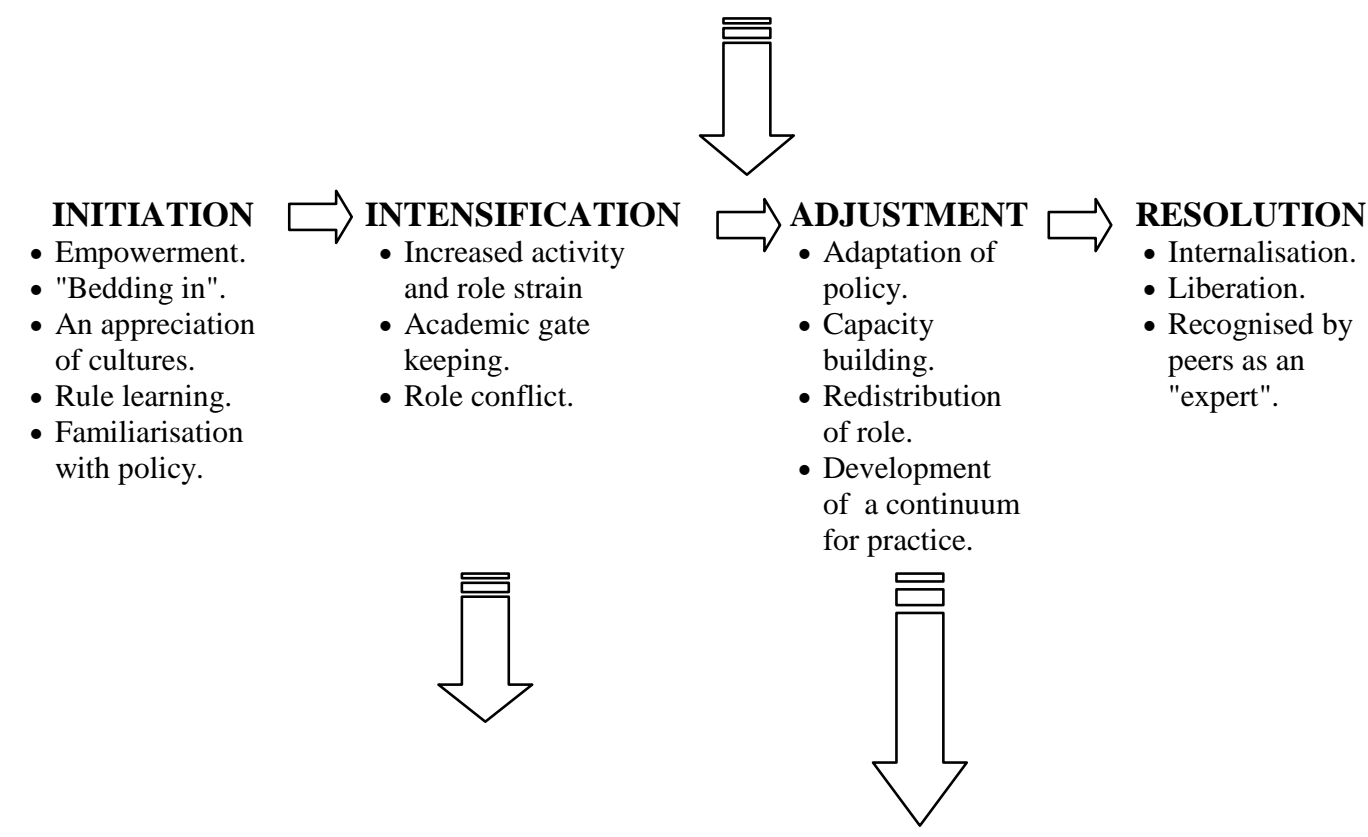

Attrition from APL activity

A Continuum for Assessment Practice

Transcripts/Certificates/Exam/Self-assessment/Profiling/Reflective essay

The Holistic Practice of RPL in UK Schools of Nursing

The practice of RPL can be described as a continuous cycle of: initiation, intensification, adjustment and resolution during which attempts are made to resolve the tension existing between the amount of time and resources available, and choice of assessment method (Table 5). For example, during initiation a period of "bedding in" occurs and an appreciation of cultures takes place. For example, one practitioner reported:

"I would have to say when the Institute of Health Studies went into the university, it was accepted that we were different, and in many instances we worked outside of university regulations. That seemed to be perfectly acceptable to the university."

During periods of increased demand or intensification novice practitioners may experience role strain, and role conflict. This may precipitate a change in 
role. For example, participants indicated they had a multi- functional role, which often gave rise to conflicting commitments:

"I'm allocated time by my job description and being an admissions tutor this has meant that I continue to teach. There are no extra RPL advisers being paid, and there has been no change to my working week."

There was also evidence that academic gate keeping had contributed towards the conflict experienced by practitioners. For example:

"I have got staff saying that we are cheapening them and that we are devaluing the teaching that they $d o^{\prime \prime}$. However, perhaps the best example of academic gate keeping emerged from the following narrative. It concerned the proposal that "listed competencies" be used as possible outcomes for RPL:

"If you adopt a developmental approach (emphasis) and develop your curriculum in terms of ... well ... what I would call a competency list ... (noise from rest of group) ... well, they (competencies) do exist ... (laughter) ..." ".

The following response was received:

"But surely, that's why the university, THE (emphasis) university curriculum ... shock, horror ... (apparent cynicism) ... has introduced ENQUIRY (emphasis) based learning?".

It appeared that these practitioners were rehearsing the arguments put forward by Butterworth (1992) in her analysis of credit based versus developmental models for RPL. Further, it appeared that each of these participants was demonstrating to others where their allegiances lay within this dichotomy. In effect they seemed to be: "Nailing their colours to the mast." (Table 5).

During the adjustment phase roles are redistributed, and attention is paid to capacity building; regulations, policy and procedure are adapted, and a continuum for practice emerges (Table 5). For example one interviewee indicated:

"Now we have changed university regulations to accommodate all the changes that the institutes are experiencing. We push boundaries within the institute, and I changed university regulations the following year to reflect that."

This phenomenon can be described as an adaptive activity, undertaken to resolve issues relating to increased demands for intensification whilst still attempting to maintain some degree of academic rigour. 
Adjustment is followed by a period of resolution (Table 5) where RPL functions become internalised and practitioners feel liberated as their expertise is recognised by peers. For example, one practitioner reported:

"... recognised as experts within the field, we've been further enabled to take the process forward. And I would say that has had a huge impact (emphasis) on our practice of RPL."

Finally, when optimal resources are available, the RPL practitioner usually adopts an assessment method that is based on the individual needs of learners, rather than the administrative requirements of the organisation. These methods are holistic and include the use of transcripts and certificates, as well as the use of profiling and reflective essays. They are inclusive, rather than exclusive, or specific to, a product or process based approach to RPL. For example, one practitioner reported:

"The actual notion of the portfolio is actually useful for new learners coming onto degree a programme. Self assessment, action planning, reflection, all of these fit very happily within portfolio assessment."

\section{How Emergent Benchmarks Inform the Career of the RPL Practitioner}

During the early stages of their career practitioners are initiated into the rules and regulations pertaining to RPL practice. It is possible that during this phase the benchmarks (Table 2) will provide greater direction for the novice practitioner. One respondent indicated that the benchmarks will help:

"...organisations identify how practitioners should be prepared for their role and ensures consistency in approach."

During periods of intensification practitioners may experience role strain or role conflict, which may result in attrition from RPL activities. Attrition could be minimised by adopting the benchmarks in order to gain greater clarity regarding the role of advisor and assessors. For example, one respondent indicated: "Benchmarks can provide fairly explicit and externally accessible statements that should facilitate quality assurance ...".

The explicit nature of the benchmarks (Table 2) will enable faculty managers to accurately assess the extent and duration of RPL activities, so that appropriate resources can be made available within the institution to support RPL activity, thereby minimising the risk of practitioner attrition. The benchmarks may also be useful in quality assuring the RPL process as they will provide a common approach towards assessment, which is both consistent and transparent.

During the adjustment phase of the practitioner's career, roles are redistributed and attention is paid to capacity building. During this phase, 
regulations, policy and procedure are adapted, and a continuum for RPL practice emerges. For example, one anonymous respondent indicated:

"... benchmarks serve to advance the self-awareness and reflexivity of practitioners. By encouraging practitioners to probe, reflect on and improve they can help to build up a consensual body of values, criteria and ways of doing things."

This respondent captures the dynamic and reflective nature of the benchmarking process and how this might serve as a basis for further development during the adjustment phase of the practitioner's career.

During the resolution phase RPL functions become internalised by the practitioner. During this phase practitioners feel liberated as their expertise is recognised by peers. For example, one practitioner thought that the emerging benchmarks would:

"... enable practitioners to function with a degree of confidence and ensures consistency in all institutions signed up to the benchmark."

The readers' attention is drawn to the suggestion (here) that there may be a relationship between the use of benchmarks for practice and the ability to practice in a confident manner. In this sense, the agreed benchmarks could become indicators for success.

\section{Trustworthiness}

Babbie and Mouton (2007) outline strategies used in social research to ensure "Trustworthiness". These include: credibility; transferability; dependability and confirmability. In this study, strategies to achieve credibility include the use of: research methods that have already been tried and tested (CAPLA 2000); informants from different geographical regions; and multiple research methods such as survey, focus group and depth interviews - what Bryman (2012) refers to as triangulation.

Tactics to ensure the honesty of informants were also developed e.g. the use of activity sheets and iterative questioning during focus group and depth interviews. In addition: informants were asked to check focus group and interview transcripts against the emergent themes for accuracy, while the results of the study were presented for discussion and peer review at conference (Day 2011b).

With regard to credibility, a comparison with previous literature has been made to test interpretations and emergent theories. For example, the emergent career pathway of the RPL practitioner is consistent with the literature on the: "Career Life Cycle" and there are strong comparisons to be made between the outcomes of this study and the work of Steffy et al. (2000) who have identified the Career Life Cycle of the professional teacher i.e. from: novice; apprentice; through to expert. 
With regard to: transferability and dependability include: an explanation of emergent models for practice has allowed for comparisons of RPL practice to be made; and a detailed account of the sampling framework and an in-depth methodological description has been given to allow the study to be repeated. It is accepted that sample size was restricted by the application of inclusion criteria and that a larger sample could have been be identified had these criteria not been applied. Nevertheless, this work is representative of RPL practice within a significant number of UK Schools of Nursing, with the exception of Scotland.

Finally, confirmability has been achieved through: the use of methodological triangulation, which included the use of survey, focus group and depth interviews. In addition, an account of the researcher's beliefs and assumptions about the nature of the research problem; and the use of tables and diagrams to provide an "audit trail" of activities and findings as they have emerged, are also provided.

\section{Discussion}

The emergence of a market led culture for UK higher education (Yokahama 2010) has encouraged managers to develop and modify the purpose and function of higher education institutions so that they may become more responsive to the needs of learners by improving access, giving student greater choice and offering more flexible courses. The DES (2003) has suggested that institutions could meet these demands, at least in part, through the further development of their creditbased systems. More recently, the 2011 White Paper, Higher Education Students at the Heart of the System (Department for Business Innovation and Skills 2011) has recommended the assessment and recognition of value added learning. This has implications for the recording of student achievement (Universities UK 2012), as well as the practice of RPL.

However, the idea that an individual can be awarded academic credit for nonformal and experiential prior learning remains controversial. For example, in her analysis of the culture underpinning RPL research in English higher education, Porkony (2011) refers to RPL as a marginal activity that is still seen by many as a threat to academic standards. In addition, the literature indicates that developments in RPL policy and strategy have largely been based on ideological assumptions rather than the results of any systematic inquiry (Breier 2011, Trowler 1996). Further, due to a lack of scholarly activity into RPL practice (Konrad 2010); the roles and responsibilities of the RPL practitioner have been developed in a haphazard way (Evans 2000). This uncertainty has not only added to the controversy surrounding RPL, but has added to the confusion and role strain experienced by university staff who often undertake RPL activities in addition to other teaching duties. As a consequence of this uncertainty, significant tensions underpinning RPL practice have arisen. These tensions can be resolved through the development of clear and explicit guidelines for practice using benchmarking methodology.

Data emerging from this study indicates that RPL practitioners within UK schools of nursing are inclined to utilise either a credit-based (i.e. product) or a 
process-based (i.e. developmental) approach towards RPL. Although this view supports Butterworth's classification of RPL practice there is also evidence to show that some RPL practitioners utilise both product and process-based approaches towards RPL. This finding confirms the earlier view that a continuum for RPL practice might exist (Trowler 1996). Within this continuum, RPL practitioners combine both product and process methodologies in an inclusive or holistic way to meet the individual needs of the learner, as well as the demands of the workplace. This holistic approach is underpinned by a typology of assessment methods, which are associated with a product or a process based approach. For example, product-based approaches include the use of transcripts, certificates and products from the work place; whilst process based approaches include selfassessment, profiling and the use of reflective essays. A holistic approach towards RPL recognizes the rich diversity of knowledge and learning which a learner can bring to an assessment situation. It promotes diversity and flexibility in the use of assessment methods, according to the individual needs of the learner, and across a continuum for assessment practice.

A holistic approach also recognizes the learner's right to actively engage and participate in their assessment through the process of action planning. This process is expressed through the following emergent benchmark:

\section{Activity (II) Agree and review an action plan for demonstration of prior learning:}

a) The individual is given accurate advice and appropriate encouragement to enable him or her to form realistic expectations of the value of his or her prior learning.

b) Any outcomes to be achieved are appropriate to the individual's prior learning and future aspirations.

c) Advice to the individual accurately identifies outcomes or agreed-upon criteria which might reasonably be claimed on the basis of prior learning.

d) Opportunities to use evidence from prior learning are accurately analysed.

e) The individual plan agreed to identifies realistic targets to collect and present evidence of prior learning as efficiently as possible.

f) The individual's motivation and self-confidence is encouraged throughout.

g) If there is disagreement with the advice given, options available to the individual are explained clearly and constructively.

h) The plan is reviewed appropriately with the individual.

The holistic approach is learner focussed. The broader purpose of assessment is recognised, which places the learner at the centre of the process. This focuses on the preparation of candidates, recognising what they know, using this information as a basis for future career planning and programme delivery. A holistic approach also recognises that there are different purposes for the recognition of prior learning and that candidates should be actively involved in deciding the purpose for which they are undertaking prior learning assessment. This purpose may vary, but might include both academic and 
professional accreditation as well as demonstration of personal competence. A holistic approach recognises that RPL should ideally be the first step into a learning programme that will build on the knowledge and skills already recognised. It also locates RPL within a broader context of lifelong learning, where individual career planning and flexible programme delivery are part of the services offered.

Finally, an holistic approach consciously seeks to address the context and conditions that inform the practice of prior learning assessment these are: educational, economic, political and cultural; and challenges education institutions to re-define curriculum content and qualifications to be more inclusive of the knowledge, skills and values that have been acquired outside the formal education system. For example, Harris (2000: 76) suggests that RPL may become more inclusive if departments and faculties placed less emphasis on hierarchical forms of knowledge and traditional methods of learning delivery; and placed greater emphasis on problem solving and the application of knowledge to the learner's experience of learning at work. These assessment methods fall within the range identified by Whitaker (2011), and are in line with Harris's notion of Trojan horse RPL (Harris 1999, 2000, 2013) and the notion of transformational RPL (Osman 2004).

However, contrary to the above literature, I have also found that assessment methodology is not determined by any particular model or approach to RPL product or process. Rather, it is context dependent and influenced by the needs of the individual student, the time and resources available, and university regulations. Therefore, it is a matter of expediency that the RPL practitioner chooses to combine product and process-based approaches in order to get a closer view of the candidate's evidence and its potential creditworthiness. This is similar to the methodology used in social science research where data from several sources are examined to check results and converge on the truth - a process known as triangulation (Bryman 2012).

This study has also found that the career of the RPL practitioner progresses through a number of significant stages, including initiation, intensification, adjustment and resolution. Successful progression through each of these stages is dependent upon the influence of university regulations, the time and resources available, and the approaches taken towards RPL. These may include either product and/or process-based approaches towards assessment. Those who are unable to resolve the tensions that exist between university regulations, and the time and resources available, withdraw from practice. For example, in this study, a $23 \%$ attrition rate has been recorded (Day 2012). Practitioners that achieve resolution do so by modifying the rules and regulations of the institution and delegating RPL practitioner roles to build their capacity for assessment.

There have been previous attempts made by CAEL (Whitaker 1989), SEEC (1995) and the CLFDB (1997) to ensure that RPL is a systematic, transparent and rigorous process. However, practitioners who have participated in this study have shown an interest in the process of benchmarking and believe that emergent benchmarks will: (a) ensure that RPL becomes a defensible process; (b) improve accountability and transparency during the assessment process; (c) assist education 
managers to identify what is possible, what is feasible, and what is acceptable for RPL practice; (d) ensure consistency of approach towards assessment; and (e) provide a common understanding and communication between stakeholders; and (g) protect the rights of students and assessment service users.

For example, the benchmarks emerging from this study can be used to develop guidelines that can be used by the RPL practitioner during his or her transition from novice to expert. These guidelines include giving advice and guidance about RPL to learners, which includes the following activities:

1. Prepare the individual for assessment by:

- helping the individual to identify relevant learning,

- agreeing to and reviewing an action plan for the demonstration of prior learning, and

- helping the individual to prepare and present evidence for assessment.

The guidelines also provide a benchmark for assessment activities:

2. Assess the individual:

- progress in formative assessment activities,

- judge evidence and provide feedback, and

- contribute to making a summative assessment decision using various sources of evidence and providing appropriate feedback.

However, the use of benchmarked standards in UK higher education is controversial and is anathema to many academics, as their use can be regarded as a form of social control and is, therefore, considered to be a potential threat to academic freedom (Elliot 1992). This threat is expressed by some academics as an increased demand for performativity (Nixon 2004). However, it is my belief that there is a case for using the agreed-upon benchmarks as an adjunct to professional practice. This point has been well by one informant who stated:

"Benchmarks serve to advance the self-awareness and reflexivity of practitioners. By encouraging practitioners to probe, reflect on and improve they can help to build up a consensual body of values, criteria and ways of doing things."

For example, in this study knowledge derived from practice has identified agreed-upon benchmarks that are underpinned by a common set of values and beliefs about the nature and purpose of prior learning assessment. Therefore, it is my view that these emergent benchmarks could be used as a focus for the development of nurse teachers who are involved in undertaking RPL activities. This will ensure the RPL process becomes more transparent, open and explicit, and will enable practitioners and their managers to signpost the changing resource requirements for RPL capacity-building during the critical phase of 
adjustment. This in turn, will ensure that RPL practitioners are adequately supported during their transition from novice to expert and may well assist in minimising practitioner attrition.

However, there is a more radical view of what professional development might mean for the teacher within higher education, as expressed by Sachs (2003) in her politically motivated account of the activist teacher. For example, Sachs (2003) argues that teachers should take ownership of their profession by creating their own standards and milestones for continuing development. Therefore, drawing upon the work of Sachs (2003), I argue that emergent benchmarks can be used as a mechanism for professionalising RPL activities undertaken by teachers within the higher education sector. Previous attempts to do this have included the development of a code of practice by SEEC and guidelines for the assessment of prior learning by the Quality Assurance Agency for Higher Education or QAA. However, the work of the QAA (2004, 2013) appears to be more institutionally focussed, concerned with the rules and regulations governing the accreditation of prior learning rather than the practice of assessment. Therefore, I am arguing that the agreed-upon benchmarks that have emerged from this study be adopted as a code of practice for nurse teachers who perform RPL activities within schools of nursing. This will provide a framework for practice that is based on a common set of values and beliefs about the nature and purpose of prior learning assessment that has emerged from the reflective and collective experience of RPL practitioners.

There are limitations to this study. For example, the emergent benchmarks may not have applicability for every professional group within higher education, particularly as the sample for this study was restricted to the field of nursing. Therefore, it is possible that the outcomes of my research can only be applied to this particular discipline within higher education. However, given the influence that practitioners within schools of nursing have had on the development of RPL policy and practice (Johnson 2002), and the lead that nursing has taken in the development of RPL within the English higher education system (Porkony 2006, 2011), there is some evidence to suggest that the benchmarks emerging from this research have a degree of applicability to other healthcare disciplines. Also, there may be some cultural or philosophical barriers that could impact upon the implementation of emergent benchmarks as a code of practice; therefore, disciplines outside the field of healthcare undertake a thorough and systematic review of these prior to their adoption. For example, Harris (2000) suggests it is critical for departments to review their beliefs and assumptions concerning the nature of knowledge and associated mechanisms for teaching, learning and assessment prior to implementing any RPL activity. This systematic and analytical approach to RPL capacity-building will ensure that the benchmarks and guidelines that have emerged from my work can be implemented in a way that is sensitive to the needs of the organisation as well as the professional development needs of the lecturer. 


\section{Conclusion}

This 15 year study has used quality assurance processes from business and industry to benchmark the role of the RPL practitioner so that the process of assessment can be made explicit to all involved in the RPL process. Three research questions were posed: what principles are common to RPL practice; can these principles be developed as benchmarks to make RPL practice more explicit, and how might emergent benchmarks inform the career of the RPL practitioner? The answers to the first two questions are reported in Day (2001a, 2001b) and Day (2011a, 2012). This paper focuses on the third research question. That is: how might emergent benchmarks inform the career of the RPL practitioner?

A career pathway for the RPL practitioner has been identified, which outlines the characteristic way in which the RPL practitioner engages with the institution to influence and develop assessment practice. A framework for practice has also been identified, based on emergent benchmarks for RPL. This framework can be used in a complementary way to underpin the career of the RPL practitioner and create a model for RPL practice. This model will locate and contextualise RPL practice and will enable institutions to build capacity for RPL. It will also enable the practitioner to reflect on, and to modify, their own practice. For example, during the early stages of the practitioner's career (initiation) the model will lend greater clarity, and give direction to, the practitioner's new role. Also, when practitioners experience role strain or role conflict (intensification) the model will give greater clarity to the role of the RPL advisor and assessor and enable managers to accurately assess the extent and duration of RPL activities, so that appropriate resources can be made available within the institution to support RPL activity. This will assist in minimising the risk of practitioner attrition. Finally, the emerging model will also be useful in quality assuring the RPL process as it will provide a common approach towards assessment, which is both consistent and transparent.

\section{Acknowledgements}

With thanks to the Clute Institute, USA.

\section{References}

Andersson P (2006) Different faces and functions of RPL: An assessment perspective, in Re-theorising the recognition of prior learning. In: $\mathrm{P}$ Andersson, $\mathrm{J}$ Harris (Edn.) National Institute for Adult and Continuing Education, Leicester, UK, pp. 31-50.

Andersson P, Fejes A (2011) Sweden: The developing field of Validation research. In: $\mathrm{J}$ Harris, M Breier, C Wihak (Edn.), Researching the recognition of prior learning. International perspectives. National Institute of Adult Continuing Education, Leicester, UK, pp. 228-247. 
Babbie E, Mouton J (2007) The practice of Social Research. (11 $1^{\text {th }}$ edn.). Cape Town: Oxford University Press.

Breier M (2011) South Africa: Research reflecting critically on recognition of prior learning (RPL) research and practice. In: J Harris, M Breier, C Wihak (Edn.), Researching the recognition of prior learning. International perspectives. National Institute of Adult Continuing Education, Leicester, UK.

Bryman A (2012) Social research methods. ( $4^{\text {th }}$ edn.). London, UK: Oxford University Press.

Butterworth C (1992) More than one bite at the APEL: contrasting models of accrediting prior learning. Journal of Further and Higher Education 16(3): 3951.

CAPLA - Canadian Association for Prior Learning Assessment (2000) Developing Benchmarks for Prior Learning Assessment. Ontario: Peace Tree Printing.

CLFDB - Canadian Labour Force Development Board (1997) National PLAR standards. Retrieved from http://goo.gl/JKmwiP.

Cameron R (2011) Australia: An overview of 20 years of research into the recognition of prior learning (RPL). In: J Harris, M Breier, C Wihak (Edn.), Researching the recognition of prior learning. International perspectives. National Institute of Adult Continuing Education, Leicester, UK, pp.14-43.

Day M (2001a) Developing benchmarks for prior learning assessment. Part 1: Research. Nursing Standard 15(34): 37-44.

Day M (2001b) Developing benchmarks for prior learning assessment. Part 2: Practitioners. Nursing Standard 15(35): 38-44.

Day M, Gawe N (2003) Developing a strategy for recognition of prior learning. A case study. Paper presented at the 14th Annual PLA Conference. Bellville, Ontario, Canada.

Day M (2011a) Developing Benchmarks for Prior Learning Assessment. An Exploratory Study. American Journal of Health Sciences 2(2).

Day M (2011b) Developing Benchmarks for Prior Learning Assessment: An Holistic Approach to the Assessment of Prior Learning. NET2011. 22nd International Networking for Education in Healthcare Conference, Churchill College University Cambridge, 6-8 September 2011.

Day M (2012) Developing benchmarks for prior learning assessment. The case for nurse education. American Journal Health Sciences 3(1): 84-95.

Day M (2013) Assessment of prior learning a practitioners guide. ( $2^{\text {nd }}$ edn. $)$. Andover: Cengage Learning.

Day M (2015a) Influencing Practice through the Development of Clear and transparent Guidelines for Recognition of Prior Learning: The Case for Nurse Education. University Sunderland, England.

Day M (2015b) Influencing Practice through the Development of Clear and Transparent Guidelines for Assessment of Prior Learning: The Case for Nurse Education. University Sunderland, England.

DES - Department for Education and Skills 2003. The Future of Higher Education. Creating Opportunity, Releasing Potential, Achieving Excellence. White Paper. CMM 5735.

Department for Business Innovation and Skills 2011. Higher education: Students at the heart of the system. Department for Business Innovation and Skills, London, UK.

DH Research and Development Directorate (England); National Institute for Social Care and Health Research (Wales); Chief Scientist Office (Scotland); R\&D Division, Public Health Agency (Northern Ireland). 2011. Governance 
arrangements for research ethics committees: a harmonised edition. Retrieved from http://goo.gl/unK0VY.

Department for Health 2010. Essence of Care. The Stationery Office, London.

Elliot J (1992) Action Research for Educational Change. Philadelphia: Open University Press, Milton Keynes.

Evans N (2000) The Evolution of AP(E) L in England. In: N Evans (Edn.), Experiential Learning Around the World: Employability and the Global Economy. London: Jessica Kingsley.

Friesen N (2011) Reflections on research for an emergent field. Endword, In: J Harris, $\mathrm{M}$ Breier, C Wihak (Edn.), Researching the recognition of prior learning. International perspectives. National Institute of Adult Continuing Education, Leicester, UK, pp.325-329.

Harris J (1999) Ways of seeing the recognition of prior learning (RPL): What contribution can such practices make to social inclusion? Studies in the Education of Adults 31(2): 124-139.

Harris J (2000) RPL: Power, Pedagogy and Possibility. Human Sciences Research Council. Pretoria, South Africa.

Harris J (2013) Ways of seeing the recognition of prior learning (RPL): What contributions can such practices make to social inclusion? Prior Learning Assessment Inside Out 2(1).

Harris J, Wihak C (2011) Introduction and overview of chapters. In: J Harris, M Breier, C Wihak (Edn.), Researching the recognition of prior learning. International perspectives. National Institute of Adult Continuing Education, Leicester, UK, pp.1-13.

HEFCE - Higher Education Funding Council for England 2010. About us: Glossary Retrieved from http://goo.gl/R4n5I9.

Johnson B (2002) Models of APEL and Quality Assurance. Southern England Consortium for Credit Accumulation and Transfer, SEEC. Cravitz Printing Co. Ltd, Brentwood, Essex.

Joosten-ten Brinke D, Sluijsmans DMA, Brand-Gruwel S, Jochems WM (2008) The quality of procedures to assess credit prior learning: implications for design. Educational Research Review 3: 51-65.

Konrad J (2010) An overview of European research on the recognition of prior learning (RPL) 2000-2010. Education-Line 1-10.

Lafont P, Pariat M (2012) Review of the recognition of Prior Learning in Member States of Europe. March 2012, Department of Education and Social Sciences, University of Paris.

Long G (2010) NMC requirements, guidance and advice for accreditation of prior experiential learning (APEL) in new pre-registration nursing programmes. APEL Guidance 050710. Nursing and Midwifery Council, London.

Manoudi A (2007) European inventory on validation of non-formal and informal learning in Greece. C3342, Dec. Ecotec, Birmingham.

Merrifield J, McIntyre D, Osaigbov R (2000) Mapping APEL: Accreditation of prior experiential learning in English higher education. Learning from Experience Trust, Goldsmiths College, London, UK.

NIACE - National Institute for Adult Continuing Education 2008 Accreditation and Recognition of Prior Experience and Learning JISC Funded Project, July, Leicester.

Nixon J (2004) A Profession in Crisis? Chapter 31. In: D Hayes, Key Debates in Education. London: Routledge Falmer. 
Osman R (2004) Access, equity and justice: Three perspectives on recognition of prior learning (RPL) in higher education. Perspectives in Education 22(4): 139-145.

Peters H (2006) Using critical discourse analysis to illuminate power and knowledge in RPL In: P Andersson, J Harris (Edn.) Re-theorising the recognition of prior learning. National Institute for Adult and Continuing Education, Leicester, UK, pp. 163-182.

Popova-Gonci V (2009) All Work and No PLA Makes Jack a Dull Boy. The Journal of Continuing Higher Education 57(1): 42-44.

Porkony H (2006) Recognising prior learning: What do we know? In: P Andersson, J Harris (Eds.), Re-theorising the recognition of prior learning. National Institute for Adult Continuing Education, Leicester, UK, pp. 261-228.

Porkony H (2011) England: Accreditation of prior learning (APEL) research in higher education. In: J Harris, B Mignonne, $\mathrm{C}$ Wihak (Eds.), Researching the recognition of prior learning. International perspectives. National Institute for Adult Continuing Education, Leicester, UK, pp. 106-126.

QAA (2000) Code of practice for the assurance of academic quality and standards in higher education. Section 6: Assessment of Students. May. Quality Assurance Agency for Higher Education. Gloucester.

QAA (2001) The framework for higher educational qualifications in England, Wales and Northern Ireland. Quality Assurance Agency for Higher Education. Gloucester.

QAA (2004) Guidelines for the Accreditation of Prior Learning. QAA 064 09/04. Quality Assurance Agency for Higher Education. Gloucester.

QAA (2013) UK quality code for higher education-Chapter B6: Assessment of students and the recognition of prior learning. Quality Assurance Agency for Higher Education, London, UK.

Sachs J (2003) The Activist Teaching Profession. Buckingham: Open University Press.

Scott I (2010) Accreditation of Prior Learning in pre-registration nursing programmes. Nurse Education Today 30: 438-442.

SEEC (1995) A Quality Code for AP(E)L Issues for Managers and Practitioners. Proceedings of the SEEC National Conference. 6th December 1995. Southern England Consortium for Credit Accumulation and Transfer. Regents College, London.

Steffy BE, Wolfe MP, Pasch SH, Enz BJ (2000) Life Cycle of the Career Teacher. Sage. California.

Short courses portal (2016) 7 Top ranked universities in Greece. Retrieved from http://goo.gl/tmG9uR.

Strauss L, Corbin J (1998) Basics of qualitative research: Grounded theory procedures and techniques. $\left(2^{\text {nd }}\right.$ edn.). Newbury Park, CA: Sage.

Sweygers A, Soeteweya K, Meeusb W, Struyfb E, Pietersa B (2009) Portfolios for Prior Learning Assessment: Caught Between Diversity and Standardization. The Journal of Continuing Higher Education 57(2): 92-103.

Travers NL (2011) United States of America: Prior learning assessment (PLA) research in colleges and universities. In: J Harris, M Breier, C Wihak (Edn.), Researching the recognition of prior learning. International perspectives. National Institute of Adult Continuing Education, Leicester, UK, pp. 248-283.

Trowler P (1996) Angels in marble? Accrediting prior experiential learning in higher education. Studies in Higher Education 21(1): 17-30.

Universities UK (2012) Introducing the hear. The final report of the Burgess implementation steering group. Universities UK, London, UK. 
Van Cleef J (2011) Canada: A typology of prior learning assessment and recognition (PLAR) research in context. In: J Harris, M Breier, C Wihak (Edn.), Researching the recognition of prior learning. International perspectives. National Institute of Adult Continuing Education, Leicester, UK, pp. 44-85.

West L, Fraser W (1993) Experience matters: The use of APEL in university admissions. Journal of Access Studies 8(1): 39-51.

Whitaker UG (1989) Assessing learning: Standards, principles and procedures. PA Council for Adult and Experiential Learning, Philadelphia.

Whitaker R (2011) Scotland: Recognition of prior learning (RPL) research within a national credit and qualifications framework. In: J Harris, M Breier, C Wihak (Edn.), Researching the recognition of prior learning. International perspectives. National Institute of Adult Continuing Education, Leicester, UK, pp. 172-199.

Wihak C (2012) What counts as research? Prior Learning Assessment Inside Out 1(2). Retrieved from http://goo.gl/58HDjK.

Yokohama K (2010) Government policy and ideology. Higher education's changing boundaries in two island kingdoms - Japan and England. Baltimore, MA: University Press. 